\title{
GCU
}

Glasgow Caledonian

University

University for the Common Good

\section{Development of eco-engineering sector specific routines and curricula for the Mediterranean region}

Mickovski, Slobodan B.; Tardio Cerrillo, Guillermo; Sangalli, Paola; Perez, Jerome; Thomson, Craig S.; Gallagher, Caroline

Published in:

Recent Advances in Environmental Science from the Euro-Mediterranean and Surrounding Regions

DOI:

10.1007/978-3-319-70548-4_272

Publication date:

2018

Document Version

Author accepted manuscript

Link to publication in ResearchOnline

Citation for published version (Harvard):

Mickovski, SB, Tardio Cerrillo, G, Sangalli, P, Perez, J, Thomson, CS \& Gallagher, C 2018, Development of ecoengineering sector specific routines and curricula for the Mediterranean region. in Recent Advances in Environmental Science from the Euro-Mediterranean and Surrounding Regions. Advances in Science,

Technology \& Innovation, Springer, Euro-Mediterannean Conference for Environmental Integration, Sousse, Tunisia, 22/12/17. https://doi.org/10.1007/978-3-319-70548-4_272

\section{General rights}

Copyright and moral rights for the publications made accessible in the public portal are retained by the authors and/or other copyright owners and it is a condition of accessing publications that users recognise and abide by the legal requirements associated with these rights.

Take down policy

If you believe that this document breaches copyright please view our takedown policy at https://edshare.gcu.ac.uk/id/eprint/5179 for details

of how to contact us. 


\title{
Development of eco-engineering sector specific routines and curricula for the Mediterranean region
}

\author{
S.B.Mickovski ${ }^{1}$, G. Tardio Cerrillo ${ }^{2}$, P. Sangalli ${ }^{3}$, J. Perez ${ }^{4}$, C.S. Thomson ${ }^{1}$, C. Gallagher ${ }^{1}$ \\ ${ }^{1}$ Glasgow CaledonianUniversity, Scotland, UK \\ ${ }^{2}$ Technical University of Madrid, Spain \\ ${ }^{3}$ Sangalli y Coronel Asociados \\ ${ }^{4}$ Institut de Recherche pour le Développement, AMAP, INRA, CNRS, CIRAD, Montpellier University, France
}

\begin{abstract}
Highlights: Eco-enginering integrates soils, plants, and water bodies to provide resilience against climate change. The ecoengineering specialisation and skills level in the Mediterraniean can be enhanced by introducing relevant curriculum for students and practitioners. Preliminary studies across the sector suggest that learning and motivational theories can be efficiently employed to close the skills gap and develop the next generation of multi-disciplinary scientists and engineers.
\end{abstract}

Keywords: eco-engineering, ground bioengineering, erosion protection, slope stability, curriculum dev't, professional dev't.

\section{Introduction}

Mediterranean coastal region contains large high density urban populations and supports diverse ecosystems. However, many of the countries in the region are being negatively affected by climate change in terms of increased flooding and erosion as the coasts fall below normal high-tide levels, as well as an increase in the number and occurrence of landslides due to changing rainfall patterns (Gonzalez-Ollauri and Mickovski, 2017). Through the Soil Thematic Strategy (Directive 2004/35/CE and COM(2006) 231/232) and 'The State of Soil in Europe' (EUR $25186 \mathrm{EN}$ ), the EU has been developing a strategic policy for soil protection and damage recovery, clearly stressing the importance of the preservation and adequate management of the soil resource throughout Europe, including its direct neighbours based on a robust integrated learning programme.

Ecological engineering is an emerging field of research concerned with the application of soils, plants, and water bodies in engineering design in order to prevent and mitigate against natural disasters. This holistic approach to solving engineering problems is seen as more sustainable then 'hard' engineered solutions. Ecologically based approaches currently represent a very small percentage of the stabilisation works undertaken due largely to gap in awareness and skills amongst practitioners (Stokes et al, 2014). As part of the ECOMED project the skills gap within the industry were researched in order to develop solutions and training aimed at specialisation within the Mediterranean Ecoengineering sector.

\section{Material and Methods}

At the preparatory stage of the project, preliminary surveys of existing curricula at educational institutions, as well as a practical training within the eco-engineering and geotechnical sector accross the northern Mediterranean was conducted and followed by a thorough analysis from the aspect of learning theory and motivation expectancy theory (Vroom, 1964). These surveys covered the ways how the practice is organized for students in relation to the current needs for specialization in the sector and were used as a basis for detailed sector needs assessment and development of specialisation curriculum.

\section{Results and Discussion}

Through the analysis, educational practices that need to change to embrace ecoengineering use in Mediterranean scenarios were identified together with gaps in the existing standards, routines and protocols of the sector (Tardio and Mickovski, 2016). The analysis suggested that posing an eco-engineering problem within academic or professional development context may not be motivating enough. In the curriculum design there should be a clear definition of the effort which will lead to rewards for the student for which an introduction and discussion on subject-specific problem solving (Figure 1) wil be needed. Setting up an achievable goal and positive reinforcement 
throughout the training would provide the expectancy, while the instrumentality can be achieved through individual/group work and engaging in consultations with the academics/practitioners.

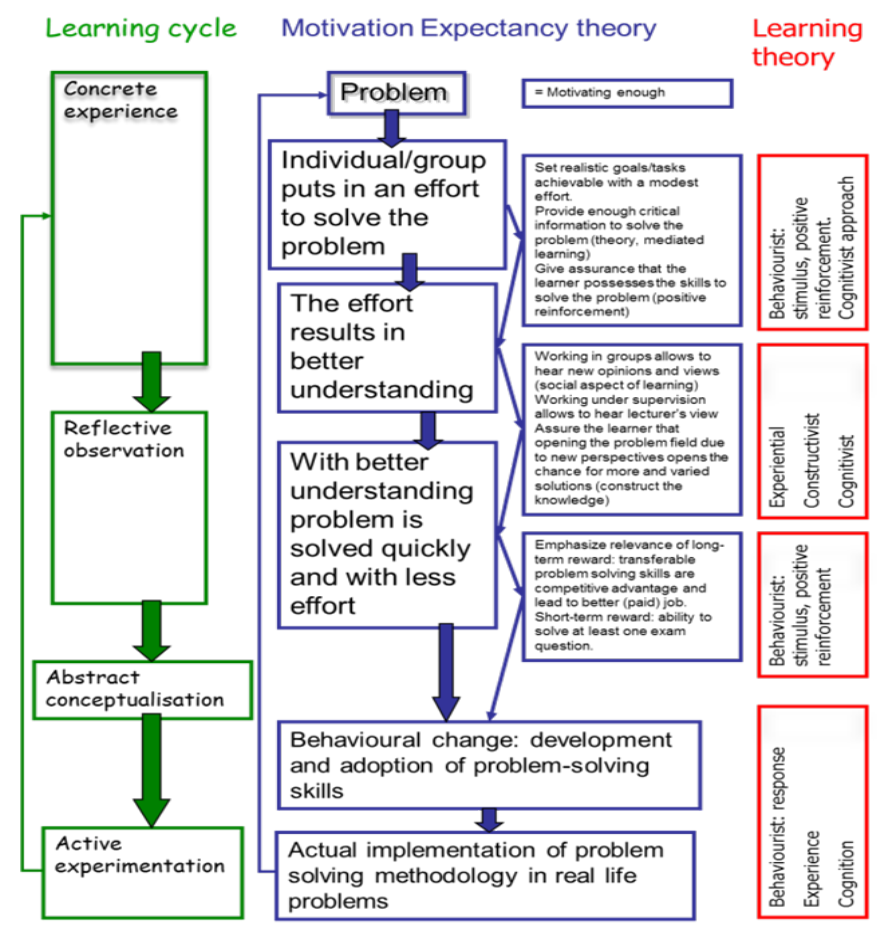

Figure 1. Systematic approach towards eco-engineering curriculum development for the Mediterranean region

Given the semi-empirical nature of eco-engineering, the accumulated experience within the sector throughout the Mediterranean environment can be exploited by recording (un)sucessful case studies as well as protocol and approaches which will form part of the curriculum. The analysis of existing eco-engineering works and projects in the Mediterranean ecoregion represents an essential source of information for developing more effective theoretical-pactical tools and syllabus which, in turn, will support the specialisation process of the eco-engineering sector (Figure 2).

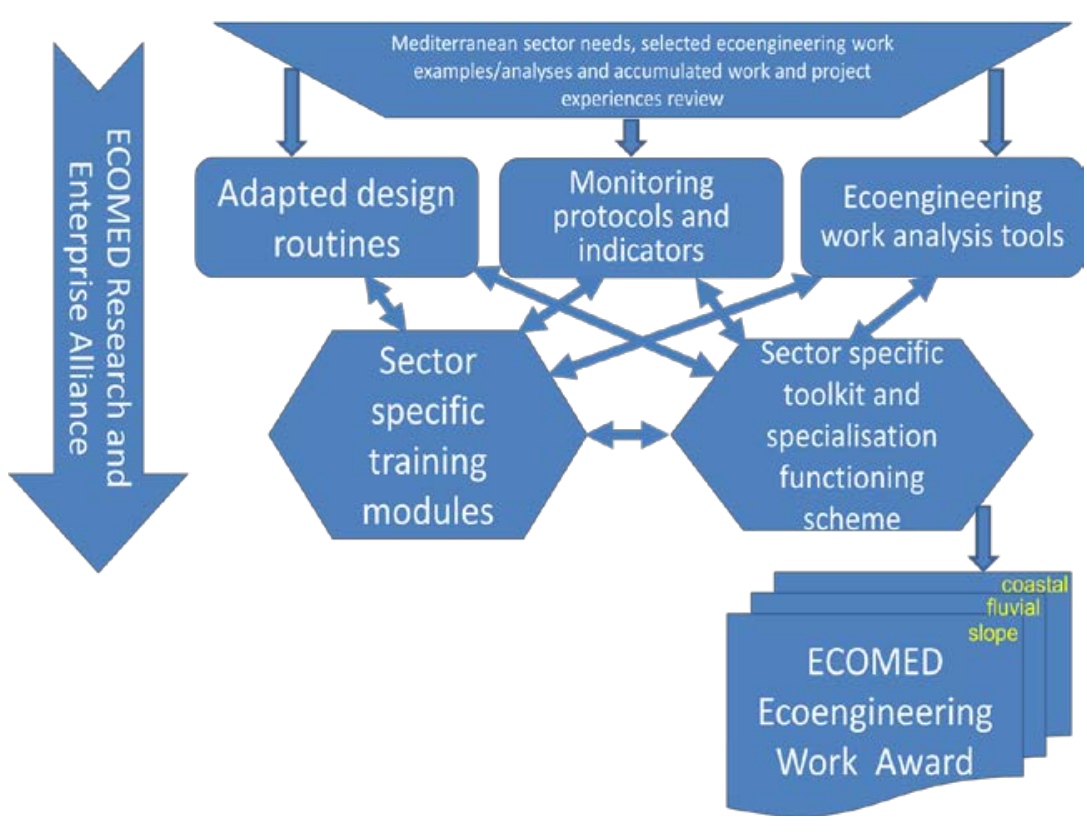

Figure 2. Development of the industry-academia alliance through the ECOMED project which will foster knowledge transfer and curriculum development. 
Based on the above, a set of modular training offers can be developed and accredited jointly/dually at the project partner institutions. The overall modular scheme will be jointly piloted by the consortium of HE partners, with the intention to offer eco-engineering training within an interdisciplinary context with endorsement and support of the enterprise partners. With this, a long-term interaction scheme between enterprises and academia will be generated which will increase the employment opportunities (e.g. internships, other applied learning) for students, but also the double-loop learning (Thomson et al, 2014) for the practitioners in the region.

\section{Conclusion}

The development of modules tailored to eco-engineering is aligned with The European Cohesion Policy 2014-2020, which promotes knowledge-based growth through diversification into technologies, products and services that are closely related to existing technologies and the regional skills base by prioritising complementarities between the economic activities and the development and transfer of advanced environmentally sound technologies and knowhow. The proposed approach will lead to a multilateral scientific programme that emphasizes the vulnerability and proactive sustainable remediation (Mickovski, 2016) of the Mediterranean region.

\section{References}

Gonzalez-Ollauri, A. and Mickovski, S.B., 2017. Hydrological effect of vegetation against rainfall-induced landslides. Journal of Hydrology, 549 (374-387);

Mickovski, S.B. 2016. Why is the future ready for Environmental Geotechnics? Environmental Geotechnics 3, 6364.

Stokes, A et al. 2014. Ecological mitigation of hillslope instability: ten key issues facing researchers and practitioners. Plant and Soil 377(1-2): 1-23

Tardio, G. and Mickovski S.B. 2016. Implementation of eco-engineering design into existing slope stability design practices. Ecological Engineering 92: 138-147

Thomson, C, Mickovski, S and Orr, C (2014) Promoting double loop learning in flood risk management in the Scottish context In: Raiden, A B and Aboagye-Nimo, E (Eds) Procs 30th Annual ARCOM Conference, 1-3 September 2014, Portsmouth, UK, Association of Researchers in Construction Management, 1185-1194.

Vroom, V.H. (1964). Work and motivation. New York, NY: Wiley. 